\title{
Management of stroke in emergency department in relation to blood pressure, blood sugar and use of anti-thrombotic agents
}

\author{
M. Aryal, S. Niraula, R. Shahukhal, N. R. Mainali, S. Sigdel, S. Giri, S. Pandey, Y. L. Shakya \\ Institute of Medicine, Tribhuvan University Teaching Hospital, Kathmandu, Nepal \\ Correspondence to: Dr. Madan Aryal, Institute of Medicine, Kathmandu, Nepal \\ Email: aryal.madan@gmail.com
}

\begin{abstract}
Introduction: Since the Emergency Department (ED) of TUTH lacks uniformity in the treatment of stroke patients, it is assumed that these patients do not receive standard treatment in terms of reduction of blood pressure (BP), control of hyperglycemia and treatment with antithrombotic agents. Our hospital-based study aims to assess the mean stay of stroke patients in the ED and the level of optimal treatment they are getting.
\end{abstract}

Methods: A retrospective hospital-based study among 82 patients diagnosed as CVA in the ED (who later got admitted), was carried out using medical records. History, clinical examinations, investigations and treatment given were analysed to gather relevant information.

Results: Mean age of occurrence of stroke in the inpatients visiting ED was found to be 62.4 years. Average duration of stay in the ED before admission was 13 hours. Ischaemic stroke was almost four times more common than haemorrhagic stoke. All the patients with haemorrhagic stroke who had indication for reduction in BPreceived antihypertensive medications. However, 28\% of the patients with ischaemic stroke, eventhough having indication for BP reduction, did not receive antihypertensives. Out of 11 patients who had an indication for reduction in blood sugar, only one patient (9\%) received treatment with insulin. Only 52\% of the patients who had ischaemic stroke received treatment with aspirin.

Conclusions: There is lack of uniformity regarding the treatment of stroke in terms of blood pressure reduction, hyperglycemia and antithrombotic treatment. A standard protocol needs to be developed in order to bring uniformity and efficiency in the treatment of stroke.

Keywords: Anti-thrombotic agents, blood pressure, emergency department, stroke

\section{Introduction}

Stroke is not only a common medical emergency but also the most common cause of severe physical disability and death in developed world after cancer and ischemic heart disease. ${ }^{1,2}$ The most common risk factors for stroke in Nepalese population were found to be smoking, hypertension, alcohol intake, atrial fibrillation and diabetes mellitus. $^{3}$

A stroke or CVA is defined by the abrupt onset of a neurological deficit that is attributable to a focal vascular cause. ${ }^{2}$ CVA includes ischemic stroke, hemorrhagic stroke and other cerebrovascular anomalies. CT imaging of the brain is the standard imaging modality to detect the presence or absence of intracranial haemorrhage. Rapid evaluation is essential for use of time sensitive treatments such as thrombolysis.?

Management of CVA is aimed at minimising the volume of brain that is irreversibly damaged, preventing complications, reducing patient disability and handicap through 
rehabilitation and reducing the risk of recurrent episodes.

Timely and proper management in specialised stroke units can make a significant difference in long term outcome, morbidity and mortality. ${ }^{4}$ There is delay in the admission of the stroke patients in the specialised units and many patients have to stay in the emergency department of TUTH for a long period of time. Therefore, proper management of stroke patients in the emergency department seems essential.

\section{Methods}

This was a descriptive study based on hospital records of stroke patients visiting ED and who later got admitted in TUTH during May 2008 to October 2008, over a period of six months. Patients were diagnosed to have stroke on the basis of clinical presentation, neurological deficits and CT scan findings. Emergency management of the patients were analysed from emergency hospital records. Necessary investigations were referred from the inpatient record. A semi-structured guideline was used to facilitate collection of information about demography of patients and management of aforementioned topics in the ED. Informed consent was taken from the head of department of emergency. The information was compiled and data was analysed using microsoft excel.

\section{Results}

Out of 82 patients included in our study, 65(79\%) had ischaemic stroke and 17(21\%) had haemorrhagic stroke. Most of the patients were males (57) with 25 females and the sex ratio was 2.28:1 (Table 1 ). In both the sexes, ischaemic stroke was more common. The mean age of occurrence was 62 years (Table 2). The youngest patient recorded was 23 years following mitral valve replacement. The maximum numbers of patients were between the ages 51 to 60 years.

Table 1: Sex distribution of stroke

$\begin{array}{llll}\text { Type of Stroke } & \text { Male } & \text { Female } & \text { Total } \\ \text { Ischemic } & 44 & 21 & 65 \\ \text { Hemorrhagic } & 13 & 4 & 17 \\ \text { Total } & 57(69) & 25(31) & 82(100)\end{array}$

Table 2: Age distribution of stroke

$\begin{array}{lll}\text { Age } & \text { No. of patients } & (\%) \\ 21-30 & 3 & (3.6) \\ 31-40 & 1 & (0.1) \\ 41-50 & 14 & (17) \\ 51-60 & 21 & (25.6) \\ 61-70 & 14 & (17) \\ 71-80 & 18 & (21.9) \\ \text { e”81 } & 11 & (13.4)\end{array}$

Average duration of stay of patients in ED before admission was 13 hours (Table 3 ). The maximum number of patients got admitted within 7 to 12 hours.

Table 3: Time taken from ED to the inpatient medical ward in hours

\begin{tabular}{lll}
$\begin{array}{l}\text { Time taken from ED to } \\
\text { medical ward (in hours) }\end{array}$ & \multicolumn{2}{l}{$\begin{array}{l}\text { No.of } \\
\text { patients(\%) }\end{array}$} \\
$\leq 6$ & 14 & $(17)$ \\
$7-12$ & 46 & $(56)$ \\
$13-24$ & 19 & $(23)$ \\
$>24$ & 3 & $(4)$
\end{tabular}

Analysis of past history revealed $41(50 \%)$ of the patients to be hypertensive, out of which $33(40 \%)$ were getting medication. Among hypertensives, ischemic stroke was three times more common than haemorrhagic stroke.

Out of 27 patients who had haemorrhagic stroke, four had indication for reduction of BP (mean arterial blood pressure (MAP) more than $130 \mathrm{mmHg}$ ) and all of them were treated but none with non-vasodilating agents. Most of them were treated with furosemide.

Regarding the reduction of BP, out of 65 patients who had ischemic stroke, 11 had indication for reduction of BP (more than 185/110, concomitant MI or malignant hypertension) out of which $8(72 \%)$ received treatment (Table 4$)$. Most of them were treated with furosemide.

Table 4: Type of treatment given in haemorrhagic and ischaemic stroke

\begin{tabular}{|c|c|c|c|}
\hline $\begin{array}{l}\text { No.of } \\
\text { haemorrhagic } \\
\text { stroke }\end{array}$ & Treatment & $\begin{array}{l}\text { No.of } \\
\text { ischaemic } \\
\text { stroke }\end{array}$ & $\begin{array}{l}\text { Treatment } \\
\text { given }\end{array}$ \\
\hline 1 & Frusemide & 4 & Frusemide \\
\hline 1 & Frusemide & & \\
\hline 1 & $\begin{array}{l}\text { and nifedipine } \\
\text { Nimodinine }\end{array}$ & 1 & Enalapril \\
\hline & and mannitol & 1 & $\begin{array}{l}\text { Enalapril } \\
\text { and } \\
\text { nifedipine }\end{array}$ \\
\hline 1 & $\begin{array}{l}\text { Frusemide and } \\
\text { amlodipine }\end{array}$ & 1 & Amlodipine \\
\hline
\end{tabular}

Eight had past history of diabetes mellitus out of which four were getting treatment. Random blood sugar more than $11.1 \mathrm{mmol} / \mathrm{l}$ was observed in 12 patients, out of which only one (8.3\%) had received treatment with insulin. 
Among 65 patients with ischemic stroke, only 34(52\%) received antithrombotic agents with aspirin whereas 31(48\%) did not receive any antithrombotic treatment. The dose ranged from $75 \mathrm{mg}$ to $300 \mathrm{mg}$ (Table 5). Out of those patients who did not receive treatment, two patients were attributed for having contraindication to aspirin while in 29 patients, the reason was not known.

Table 5: Dose of aspirin used in the treatment of ischemic stroke

\begin{tabular}{ll} 
Dose of aspirin & No. of patients \\
$300 \mathrm{mg}$ & 28 \\
$150 \mathrm{mg}$ & 1 \\
$100 \mathrm{mg}$ & 2 \\
$75 \mathrm{mg}$ & 3 \\
\hline
\end{tabular}

\section{Discussion}

Our study revealed that the mean age of occurrence of stroke was 62 years and stroke was 2.2 times more common in males. Similar studies done in Nepal Medical College Teaching Hospital by Pathak V et al have showed that the mean age of occurrence was 61 years and males were more commonly affected. ${ }^{5}$ Other similar studies done showed that chances of having stroke in males is 1.25 times greater than in females. ${ }^{6}$

Our study showed that the youngest patient recorded was 23 years following mitral valve replacement. This seems to be consistent with the fact that the approximately 3 to $4 \%$ of all stroke occur within the age of 15 and 45 years. ${ }^{7}$

We found that average duration of stay of patients in ED before admission was 13 hours and the maximum number of patients got admitted within 7 to 12 hours, however many studies have shown that there can be significant difference in outcome when they are timely managed in the specialised stroke units. ${ }^{4}$

Our studies found ischaemic stroke to be 3.8 times more common than haemorrhagic stroke which is relatively higher than what previous studies have shown. In Nepal studies have shown that ischaemic stroke is 1.5 to 3 times more common than haemorrhagic stroke. ${ }^{3}$

We found that $50 \%$ patients had past history of hypertension which is consistent with the fact that it is a major risk factor for the occurrence of stroke.

Although definitive therapy of thrombotic and embolic vascular problems are usually initiated in the specialized wards, there are some general measures, however, all ED physicians can take to expediate patient recovery which also includes reduction of BP and treatment with anti thrombotic agents. ${ }^{11}$

There has been growing evidence that intraparenchymal hemorrhage may be exacerbated by acutely elevated blood pressure, and current recommendations are to lower MAP to less than $130 \mathrm{~mm} \mathrm{Hg}$ in hemorrhagic stroke. Blood pressure should be lowered with non-vasodilating IV drugs such as nicardipine, labetolol or esmolol without inducing hypotension., ${ }^{2,11}$

In our study, all of the patients who had indication for reduction of BP (MAP more than $130 \mathrm{mmHg}$ ) were treated with antihypertensives but none with non-vasodilating agents. Most of them were treated with furosemide.

However, studies have shown that diuretics such as furosemide and mannitol are useful when intracranial haemorrhage is complicated by signs of increase in intracranial pressure, worsening symptoms or impending uncal herniation. These agents move fluid from intracranial compartment thereby reducing cerebral edema. ${ }^{8,9}$

Again, it has been recommended that emergency department care and disposition for raised blood pressure include severe hypertension (systolic $\mathrm{BP}>220$ or MAP $>130 \mathrm{~mm} \mathrm{Hg}$ ) needs to be treated. Preferable agents include labetolol or enalapril. $^{10}$

However, in cases of ischaemic stroke, BP should be lowered if there is malignant hypertension or concomitant myocardial ischemia or if BP is more than 185/110 or thrombolytic therapy would be anticipated. ${ }^{2}$

In this setting, although 11 patients in our study had an indication for BP reduction, our studies showed that only $8(72 \%)$ received treatment. Most of them were treated with furosemide. In similar studies, Rosen P, et al have shown that labetolol and ACE inhibitors are given for gradual reduction of $\mathrm{BP}^{12}$

In our studies, 8 patients had prior history of diabetes. Diabetes has been shown to be one of the risk factors for stroke in Nepalese population. ${ }^{5}$ Studies have shown that hyperglycemia (blood sugar $>11.1 \mathrm{mmol} / \mathrm{l}$ ) dramatically worsens the ischaemia. So, it is reasonable to prevent hyperglycemia. Serum glucose should be monitored and kept at $6.1 \mathrm{mmol} / \mathrm{l}$ using insulin infusion. ${ }^{1}$ Contrary to this, our studies showed that out of 12 patients who had random blood sugar more than $11.1 \mathrm{mmol} / \mathrm{l}$, only one(8.3\%) received treatment with insulin.

Aspirin has proved to be, perhaps, the most consistently useful drug in the prevention of thrombotic and embolic 
stroke. ${ }^{10}$ It reduces atherosclerotic stroke morbidity and mortality. Aspirin $300 \mathrm{mg}$ should be used as soon as the ischaemic stroke or throembolic Transient ischemic attack (TIA) is confirmed, reducing to $75 \mathrm{mg}$ after several days. In patients who cannot tolerate aspirin, clopidogrel should be used. ${ }^{9,13-16}$ However, heparin, Low molecular weight heparin $(\mathrm{LMWH})$ and warfarin anticoagulation treatment is controversial and is not generally recommended for ischaemic stroke. ${ }^{11}$ Although aspirin has been the only drug that remains cornerstone in the treatment of ischaemic stroke, our studies have shown that it has been much more underutilized in our ED. Only $52 \%$ of ischaemic stroke patients received aspirin whereas $48 \%$ did not receive any forms of antithrombotic treatment. The dose ranged from $75 \mathrm{mg}$ to $300 \mathrm{mg}$. Although the cause for under utilization was indetermined in many cases, two patients out of 31 had contraindications to aspirin. However, these two patients did not receive any other forms of antithrombotic treatment.

\section{Conclusions}

There is lack of uniformity in treating stroke patients in the ED in terms of blood pressure reduction, management of hyperglycemia and antithrombotic therapy. Standard treatment of stroke which can be given by the emergency physicians has been underutilized. Following Uniform protocol in the treatment of stroke patients would help to expedite the recovery of stroke patients.

\section{Acknowledgements}

We would like to thank Dr. Vijay Raj Bhatta for going through this work and Mr. Sumit Dahal for his technical help. Our thanks go to Emergency Department, Tribhuvan University Teaching Hospital authority for letting us conduct our study.

\section{References}

1. Staessen JA, Kuznetsova T, Stolarz K. Hypertension prevalence and stroke mortality across populations. JAMA. 2003 May 14;289(18):2420-2.

2. Smith SW, English DJ, Johnston CS. Cerebrovascular diseases. Harrison's principles of internal medicine, 17th ed. New York: Mcgraw Hill Companies; 2008. p. 2513-5.

3. Devkota KC, Thapamagar SB, Malla S. Retrospective analysis of stroke and its risk factors at Nepal Medical College Teaching Hospital. Nepal Med Coll J. 2006 Dec;8(4):269-75.

4. Mohr JP, Choy DW, Grota JC, et al. Stroke. pathophysiology, diagnosis and management. 4th ed. Piladelphia: Churchil Livingstone; 2004.

5. Pathak V, Kanth R, Pant H. Stroke: a case series study in Nepal Medical College Teaching Hospital. Nepal Med Coll J. 2006 Sep;8(3):180-1.

6. Sacco RL, Benjamin EJ, Broderick JP, Dyken M, Easton JD, Feinberg WM, et al. American Heart Association Prevention Conference. IV. Prevention and Rehabilitation of Stroke. Risk factors. Stroke. 1997 Jul;28(7):1507-17.

7. Hachinskin VE, Norris JN. The young stroke. In: Davis FA, editor: The acute stroke. Philadelphia: 1985.

8. Rosey K, Allens. Increased ICP in stroke patients. Stroke clinical updates. 1994;5:1.

9. Rapper HA, Bran HR. Principles of neurology. 18th ed. New York: MC Graw Hill Companies; 2005. p. 697.

10. Adams H P, Brott TG, Furlam AJ, et al. From the special writing group of the stroke council. American heart association guidelines for medical scientific statement Dallas: American heart association; 1994.

11. Tintinalli EJ, Krome LR, Ruiz E. Emergency New York medicine. 3rd ed. New York: Mc Graw Hill; 1992. p. 795.

12. Rosen P, Barkin R, et al. Emergency medicine. 4th ed. St. Louis Mosby; p. 2190-1. (vol III)

13. Antithrombotic Trialists' Collaboration. Collaborative meta-analysis of randomised trials of antiplatelet therapy for prevention of death, myocardial infarction, and stroke in high risk patients. BMJ. 2002 Jan 12;324(7329):71-86.

14. The International Stroke Trial (IST): a randomised trial of aspirin, subcutaneous heparin, both, or neither among 19435 patients with acute ischaemic stroke. International Stroke Trial Collaborative Group. Lancet. 1997 May 1;349(9065):1569-81.

15. Ma JO, Cline MD, Tintinalli EJ, Kelen D, et al. Emergency medicine. 2nd ed. New York: Mc-Graw Hill; 2004. p. 489.

16. Adams H, Adams R, Del Zoppo G, Goldstein LB. Guidelines for the early management of patients with ischemic stroke: 2005 guidelines update a scientific statement from the Stroke Council of the American Heart Association/American Stroke Association. Stroke. 2005Apr;36(4):916-23. 